\title{
Research on clinical significance of cerebral vascular function in patients with silent cerebral infarction and risky factors.
}

\author{
Ming Yang*, Jinhua Wang, Haiyan Lin, Feifei Jiang \\ Medical Science, People's Hospital of Quzhou, Quzhou, Zhejiang, PR China
}

\begin{abstract}
Recent advancements in brain imaging technologies have facilitated the understanding on several neurological deficits. Increased cases of cerebral infarction have led scientists to focus their researches on the related topics. Silent cerebral infarctions commonly known as silent strokes are one of the poorly understood neurological deficit which still lacks a clear definition. Cerebral infarction is more apparently found in patients with silent cerebral infarction. In this paper, the concept of silent cerebral infarction was studied, and the pathology and etiology were analysed. The patients were selected as the research objects, and their cerebrovascular function was detected. The paper also analyses the correlation between risk factors and better treatment options were also discussed to make certain contributions to the progress of medicine.
\end{abstract}

Keywords: Silent cerebral infarction, Cerebrovascular function, Risk factors.

Accepted on May 22, 2017

\section{Introduction}

Cerebral infarction is one of the most common causes of brain death, while resting cerebral infarction is one of the more specific types of cerebral infarction [1]. Sometimes, patients were not found to have more significant clinical signs, but the images of the brain will show that patients have had a pathological cerebral infarction [2]. These cases of silent cerebral infarcts are called as Silent Brain Infarction (SBI). These are usually detected on MRI scans or computed tomography [3].

\section{State of the Art}

The etiology, pathogenesis and the risk factors shared by the silent cerebral infarction and symptomatic cerebral infarction are more in common. The studies reveal that two kinds of diseases can interchange from resting cerebral infarction into symptomatic cerebral infarction. The major difference between the two forms lies in the inert nature of SBI's. They usually lack stroke-like symptoms which makes them unnoticed and more risky [4].

\section{An overview of major causes of cerebral infarction}

The retrospective analysis of the major causes of silent cerebral infarction suggests that it has strong association with major risk factors such as carotid artery disease, metabolic syndromes, hypertension, homocysteinemia, chronic kidney diseases etc. (Figure 1) [5]. In hypertensive patient's blood pressure usually rises when the patient's arteries have begun to harden, and the two are usually accompanied by each other. At the same time, in patients suffering from diabetes, patient's blood lipids will increase, and these symptoms may also make the patient's artery atherosclerotic burden, thus speeding up the hardening speed. Therefore, the arteries of a patient with a diameter of more than 500 microns will harden rapidly, and the lumen of an artery in the brain of patients will gradually shrink and become narrower, so the patient will suffer from the cerebral thrombosis which can affect the health of patient's brain $[6,7]$.

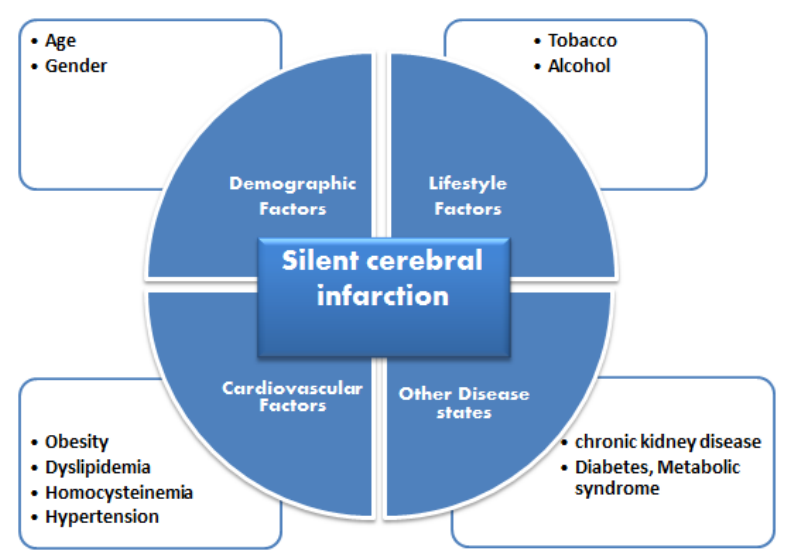

Figure 1. Risk factors associated with silent cerebral infarction.

\section{Pathological analysis of silent cerebral infarction}

The recent reports on pathological analysis of silent cerebral infarction, mentions that the possibility of SBI's in the patient's internal carotid artery accounts for $80 \%$, while the possibility 
of such a disease in the patient's vertebrobasilar artery generally accounts for a lesser percentage of about twenty. Therefore, the most likely place of resting cerebral infarction in the human body is the internal carotid artery followed by the cerebral artery, and the last one is the vertebral basilar artery. In the blood vessels of these lesions, we can observe some of the blood clots that occur after the onset of atherosclerosis, and they will hinder the entire local blood supply and cause nerve cell necrosis [8-10].

\section{Methods}

60 patients with silent cerebral infarction were divided into 3 groups for the cerebrovascular function test. At the time of detection, we found that the severity of cerebral infarction in these patients was closely related to the cerebral vascular function. The test results and the specific data collection results are shown in the following Table 1.

Table 1. Indexes of cerebrovascular function in patients with silent cerebral infarction.

\begin{tabular}{lllllllll}
\hline $\begin{array}{l}\text { Mean cerebral } \\
\text { blood flow }\end{array}$ & 1.09 & 1.05 & 1.27 & 1.23 & 0.81 & 0.58 & 0.48 & 0.43 \\
\hline $\begin{array}{l}\text { Mean blood flow } \\
\text { velocity }\end{array}$ & 168 & 179 & 135 & 189 & 206 & 292 & 362 & 387 \\
\hline $\begin{array}{l}\text { Maximum blood } \\
\text { flow velocity }\end{array}$ & 3.06 & 3.75 & 4.97 & 4.67 & 3.43 & 2.77 & 2.07 & 2.01 \\
\hline $\begin{array}{l}\text { Minimum blood } \\
\text { flow velocity }\end{array}$ & 5.32 & 4.75 & 6.67 & 5.96 & 3.56 & 2.22 & 1.57 & 1.43 \\
\hline $\begin{array}{l}\text { Cerebral vascular } \\
\text { resistance }\end{array}$ & 78 & 76 & 60 & 101 & 123 & 145 & 156 \\
\hline $\begin{array}{l}\text { Cerebral vascular } \\
\text { pressure }\end{array}$ & 1.49 & 1.59 & 2.18 & 1.87 & 1.27 & 0.95 & 0.79 & 0.76 \\
\hline $\begin{array}{l}\text { Total score of } \\
\text { cerebrovascular } \\
\text { function }\end{array}$ & 242 & 226 & 165 & 193 & 283 & 379 & 456 & 476 \\
\hline
\end{tabular}

\section{Result Analysis and Discussion}

The balanced test was carried out to the research objects and the above data was analysed. The results from this study are as follows. The study analysed various factors such as the average age of the cases, gender of the cases as well as the hemodynamic parameters of the cerebral vessels in the cases. The results showed that the minimum, maximum, mean blood flow velocity and blood flow of the patient were slowed down whereas the patient's cerebral vascular resistance and pressure showed a phenomenon of improvement. There was a significant decrease in the total score of cerebrovascular function. The following Figure 2 shows the patient's minimum, maximum, mean blood flow velocity, the patient's cerebral vascular resistance, pressure, the patient's total score of cerebrovascular function and so on.

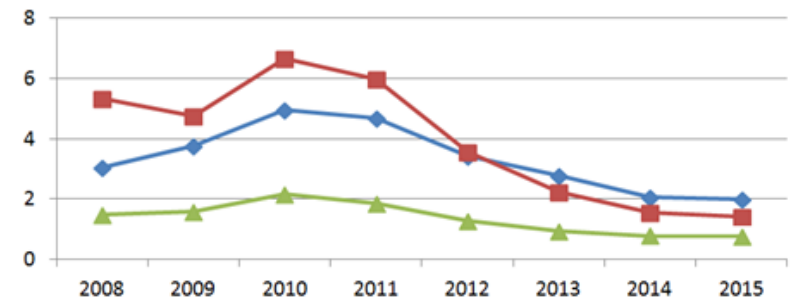

Figure 2. Comparison of detection data of cerebral vascular function in patients.

These findings of the study hint that the detection of cerebrovascular function in patients has very important clinical significances for the prevention and treatment of silent cerebral infarction.

\section{Conclusions}

With the development of the medical science, people are paying more and more attention to the health of the brain. In this paper, after the study of silent cerebral infarction theory, 60 patients with silent cerebral infarction were chosen as the research object and the function of cerebrovascular patients were detected. The clinical significance of the study on the cerebral vascular function for the prevention and treatment of cerebral infarction was analysed and the theoretical basis of silent cerebral infarction and medical treatment technologies were studied. This study can make a certain contribution to the medical advances in the treatment of silent cerebral infarction.

\section{Acknowledgments}

This work was supports by key medical talents fund of People's Hospital of Quzhou.

\section{References}

1. Gjerde G, Naess H. Risk factor burden predicts longterm mortality after cerebral infarction. Acta Neurologica Scandinavica 2014; 129: 173-177.

2. Jabbarli R, Reinhard M, Roelz R. Early identification of individuals at high risk for cerebral infarction after aneurysmal subarachnoid hemorrhage: the BEHAVIOR score. J Cereb Blood Flow Metabol 2015; 35: 1587-1592.

3. Jonathon PF, Allan JW, Andrew AW, John FF. Emerging spectra of silent brain infarction. Stroke 2014; 45: 11.

4. Vermeer, Sarah E. Silent brain infarcts: a systematic review. Lancet Neurol 2007; 6: 611-619

5. Fanning JP, Wong AA, Fraser JF. The epidemiology of silent brain infarction: a systematic review of populationbased cohorts. BMC Med 2014; 12: 119.

6. Park K, Yasuda N, Toyonaga S, Tsubosaki E, Nakabayashi H, Shimizu K. Significant associations of metabolic syndrome and its components with silent lacunar infarction in middle aged subjects. J Neurol Neurosurg Psychiatry 2008; 79: 719-721. 
factors

7. Asumi M, Yamaguchi T, Saito K, Kodama S, Miyazawa H, Matsui H, Suzuki E, Fukuda H, Sone H. Are serum cholesterol levels associated with silent brain infarcts? The Seiryo Clinic Study. Atherosclerosis 2010; 210: 674-677.

8. Olsen TS, Skriver EB, Herning M. Cause of cerebral infarction in the carotid territory. Its relation to the size and the location of the infarct and to the underlying vascular lesion. Stroke 1985; 16: 459-466.

9. Kazuo T, Ryukichi M, Shingo Y, Shotai K. Silent brain infarctions and leukoaraiosis in patients with retinal ischemia. Stroke 2001; 32: 3.

10. Steinberg GK, Drake CG, Peerless SJ. Deliberate basilar or vertebral artery occlusion in the treatment of intracranial aneurysms: Immediate results and long-term outcome in 201 patients. J Neurosurg 1993; 79: 161-173.

\section{*Correspondence to}

Ming Yang

Medical Science

People's Hospital of Quzhou

PR China 